\title{
Theoretical Model of Nanomaterial Heat Content (Energy) During Grain Refinement by Accumulative Roll-Bonding (ARB).
}

\author{
M. Pita ${ }^{1,2}$, M.P. Mashinini ${ }^{2}$, L.K. Tartibu ${ }^{2}$ \\ ${ }^{l}$ Department of Mechanical and Industrial Engineering, Faculty of Engineering and Technology, University of South Africa. \\ ${ }^{2}$ Department of Mechanical and Industrial Engineering Technology, Faculty of Engineering and the built Environment, \\ University of Johannesburg.
}

\begin{abstract}
Theoretical and experimental model of nanomaterial heat content is investigated in this research study. Theoretical model was developed based on microscopy analysis of particle size during particles refinement. Important parameters that affect particles growth like temperature and activation energy are investigated during modelling and validated experimentally. The theoretical modelled results of internal energy during ARB, work done during ARB, strain energy and yield stress during ARB show a close correlation when compared with experimental results. The material tensile stress at yield (offset $0.2 \%$ ), UTS, temperature and particle sizes were tested experimentally for validation with the theoretical modelled results. The following facts were theoretically obtained and validated experimentally. Microstructure after second ARB pass shows an interface between two particles layers which are straight and adherent due to material being piled. Different particle curvature and dislocation from $\left(1^{\text {st }}\right.$ pass to the $2^{\text {nd }}$ passes) during grain refinement was noticed and this impacted the material properties. After several rolling process, it was observed that the temperature reached $29.5^{\circ} \mathrm{C}$ and ultimate tensile strength drops. This indicated that the material changed its properties. This study revealed the following: the decrease in particle size increases material temperature. Continues increasing in surface temperature results in particle growth, material strain energy increases with time during grain deformation, the material internal heat supply increases with time during deformation of nanostructure materials, decrease in particle sizes lead to increase in internal energy during ARB, the material internal energy decreases as the particle sizes decreases during ARB. finally, the strain energy increases as the particle sizes decreases.
\end{abstract}

Keywords: heat content, energy, strain energy, and grain refinement

\section{INTRODUCTION}

Nanotechnology is a revolution, not evolution, in science and technology. It distinguishes itself from all previous scientific and industrial revolutions in many ways [1]. In recent years, aluminium alloys are widely used in automotive industries. This is particularly due to the real need to weight saving for more reduction of fuel consumption and exhaust emissions [2].
Reducing the grain size of polycrystalline metallic materials is an economic way to improve the mechanical properties such as strength, and toughness [3]. Nanomaterials are a new brand of materials with noble properties [4]. Nowadays, this class of materials is attracting continuous attention. This is due to the fact that their nanostructures can be characterised [4]. Interest has recently developed in processing bulk materials through the application of severe plastic deformation (SPD) [5]. Severe plastic deformation (SPD) methods, like equal channel angular pressing (ECAP) method, accumulative roll bonding (ARB), high pressure torsion (HPT) and cyclic extrusion compression (CEC) have been frequently applied to produce ultrafine grained (UFG) materials [6]. The possibility of producing UFG materials by repeated intense straining without much alteration of the initial dimensions has attracted great interest in recent times [7]. Among these techniques, the ARB method is suitable to fabricate UFG sheets or plates for industrial application because of high productivity rate, continuous production, and simplicity of required facilities [8]. UFG structures are assumed to possess specific mechanical properties such as strength and ductility [9]. The advances in nanomaterials modelling coupled with new characterization tools are the key to study new properties and capabilities and then to design devices with improved performance [10]. Lu and Jiang developed theoretical model for size dependent surface energy of nanocrystals, they established adjustable parameter based on the previous model for the size dependent cohesive energy [11]. Sob et al. also developed a theoretical model to evaluate the internal energy of nanocrystalline materials deformed by ARB [12]. A theoretical stochastic model of energy of nanocrystalline materials produced by Accumulative rollbonding $(\mathrm{ARB})$ and considering the intrinsic influence of bond energy on the microstructure and the change of internal energy due to "work" and heat supplied during the deformation of nanostructure material was developed by Sob et al [13]. The proposed model considered the work done in the deformation of nanostructure materials and the intrinsic influence of bonding energy and the lattice distortion energy during grain refinement of 3-D grains [13]. Theoretical model was developed by Bhatt and Kholiya to study the size and shape dependence of vibrational and thermodynamic properties of nanomaterials with focus on temperature during grain refinement [14]. Nanomaterials are very sensitive to temperature as temperature affects their properties. Temperature affects thermodynamic and kinematic properties 
which are related to the vibration energy in a material during grain refinement. Much studied have been geared on temperature but few focused on the real connection with the nanomaterials Debye temperature, Debye frequency, melting entropy, and enthalpy in different shapes during ARB. This affects fundamental properties such as surface energy of the bulk material due to the decrease in sizes which affect their vibration energy. It was reported that the surface energy falls as the size of crystals decreases to several nanometres while the surface energy ratio between different facets is sizeindependent and is equal to the corresponding bulk ratio [11]. Sob et al. reported that variation of energy during grain refinement follow an inverse proportional relationship with grain size variants during grain refinement. In addition, it appears that the energy increases is proportional to the decrease in grain size for the grain size variants[15]. The thermodynamic behaviour of nanocrystals differs from that of the corresponding bulk materials, due to the additional product of the surface excess, free energy and the surface area [11]. Therefore, it is also important to study strain energy and activation energy due to straining by ARB process which is also the main objective of the current paper.

\section{METHODOLOGY}

\subsection{ARB experiment}

The experiment was performed at the university lab, where the machine was designed and manufactured. A two-roller rolling machine was used for this experiment. An aluminum strip of $2465 \mathrm{~mm}$ length, $25 \mathrm{~mm}$ width and $1.6 \mathrm{~mm}$ thickness was used. The pressure applied between the rollers was 3.5 tons. The temperature of the material was measured with an infrared thermometer before and after rolling. The material was fed into the machine and rolled at a speed of 9 RPM. After the first pass, the temperature on the surface of the material was measured as well as the thickness as shown in table 1 . Then the material was cut into two equal pieces, cleaned with a wire brush, stack together with bonding wire, and rolled for a second time. This process of rolling, measuring the temperature, recording the thickness, cleaning and stacking was repeated twice. Before and after every ARB pass, sample material was cut for microscope observation and tensile testing. Material chemical composition is presented in table 2 .

Table 1: Number of passes, temperatures and thickness reduction before and after ARB process

\begin{tabular}{|c|c|c|}
\hline No. of passes & $\begin{array}{c}\text { Temperatures } \\
\left({ }^{\mathbf{0}} \mathbf{C}\right)\end{array}$ & $\begin{array}{c}\text { Thickness } \\
\text { reduction \% }\end{array}$ \\
\hline Original sample & 24.1 & \\
\hline 1 & 27.2 & 49 \\
\hline 2 & 29.5 & 50 \\
\hline
\end{tabular}

Table 2: Chemical composition of AL- 1050-H4 Alloy.

\begin{tabular}{|c|c|c|c|c|c|c|}
\hline Cast No. & Alloy & $\mathrm{O}(\%)$ & $\mathrm{Fe}(\%)$ & $\mathrm{Si}(\%)$ & $\mathrm{Ag} \mathrm{L}$ & $\mathrm{Al}(\%)$ \\
\hline $18122 \mathrm{~A} 44$ & 1050 & 2.66 & 0.47 & 10.27 & 1.06 & 85.54 \\
\hline
\end{tabular}

\subsection{Sample preparation}

Samples were cut, hot mounted in Bakelite on a citopress-10 at rolling direction (RD). Samples were grounded by P500, P1200 and ultimately held with a magnetic disc (MD) Largo grinding disc. Thereafter, they were washed in water and rinsed with ethanol. Samples were polished using diaduo 2 diamond paste, from 6,3 , and 1 um diamond paste, they were polished for 3 mins for each diamond paste, and with $30 \mathrm{~N}$ pressing force. Samples were washed in water and rinsed with ethanol and stored in desiccator. Barker's anodizing etching method was used on this samples. Al cathode, $13 \mathrm{~cm}$ of anode and cathode immersed in solution $10 \mathrm{~mm}$ apart was used. $0.5-1.5 \mathrm{~A} / \mathrm{in}^{2}$ and 30-45 V DC was used before observing the samples with light polarized microscope. Microstructure images of sample and after ARB passes were captured and studied. They are presented in figure $1(\mathrm{a}-\mathrm{c})$. Mean particle size of all samples were measured using ImageJ. The method used to measure mean particle sizes was line method and the results are presented in table 3 .

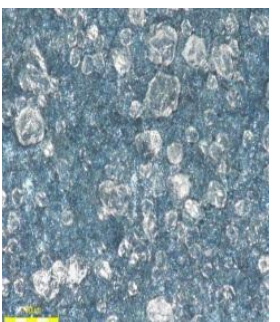

(a)

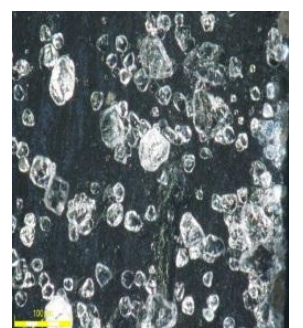

(b)

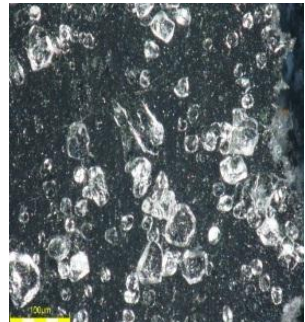

(c)
Figure 1: Light Polarized Microscope microstructure images at rolling direction (RD). (a) original sample, (b) after first pass and (c) after second pass of ARB process.

Table 3: Mean particle size at rolling direction (RD)

\begin{tabular}{|c|c|}
\hline Sample number & Mean particles $(\boldsymbol{\mu m})$ \\
\hline 0 (parent sample) & 35.03 \\
\hline 1 & 25.32 \\
\hline 2 & 32.91 \\
\hline
\end{tabular}

\subsection{Tensile test experiment}

Tensile test specimens were machined for the parent sample and samples after ARB process along the rolling direction (RD) and then tested at room temperature. The specimens were prepared following ASTM standard E8/E8M-09 (standard test methods for tension testing of metallic material) (ASTM Int. 2009). For statistical considerations, three specimens of the original sample and samples after ARB process were tested. Dimensions of tensile test samples are presented in figure 2. Tensile test was carried out on $10 \mathrm{KN}$ Instron electromechanical controlled testing machine. The machine was loaded at a crosshead velocity of $2 \mathrm{~mm} /$ minute. The specimen was finally fractured after necking. E-modulus, tensile stress at yield (offset 2\%), ultimate tensile strength (UTS) and percentage elongation data were recorded and are presented in 
table 4 (a-c). Figure 3 (a-c) represents graphically the results reported in table $4(a-c)$.

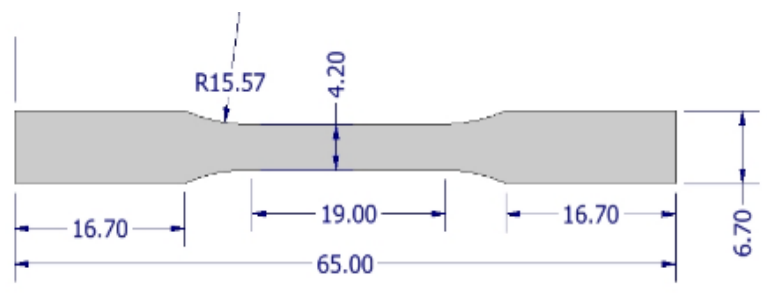

Figure 2: Tensile test specimen dimensions

\section{RESULTS AND DISCUSSION}

\subsection{Microstructure evolution along rolling direction (RD)}

The microstructure of sample before ARB process is presented in figure $1 \mathrm{a}$ at room temperature of $24.1^{\circ} \mathrm{C}$. It was observed that almost all particles are circular shape. The mean particle size of this sample found to be $35.03 \mu \mathrm{m}$ on rolling direction which is presented in table 3 . Figure $1 \mathrm{~b}$ shows the microstructure of sample after the first ARB pass. It was observed that particles are elongated along the rolling direction. It was observed that there is a reduction in particle size after first ARB pass which is reported as $25.32 \mu \mathrm{m}$ on table 3 . Also, it was observed that temperature due to friction increased to $27.2^{\circ} \mathrm{C}$ after first $\mathrm{ARB}$ pass. Microstructure after second ARB pass is shown in figure 1c. these microstructure shows an interface between two particles layers which are straight and adherent due to material being piled during second pass of ARB process in this direction. There are different particle curvature and dislocation from $1^{\text {st }}$ pass to the $2^{\text {nd }}$ passes during grain refinement and this impacted the material properties. It was observed that there is particle growth after $2^{\text {nd }}$ pass which was reported to be $32.91 \mu \mathrm{m}$. The phenomena of particles growth impacted the particle curvature, particle size and material properties. Particle growths are reported at a very early stage in AL1050-H4 material when compared to other nanocrystalline materials.

\subsection{Mechanical properties}

This section summarizes the results obtained from this investigation in tabulated format and graphically.

Table 4: Experimental data.

\begin{tabular}{|c|c|c|c|c|}
\hline \multicolumn{5}{|c|}{ (a) Parent sample before rolling } \\
\hline & $\begin{array}{l}\text { Modulus E } \\
\text { [Gpa] }\end{array}$ & $\begin{array}{l}\text { Tensile Stress at } \\
\text { Yield (offset } 0.2 \% \text { ) } \\
{[\mathrm{Mpa}]}\end{array}$ & $\begin{array}{l}\text { UTS } \\
{[\mathrm{Mpa}]}\end{array}$ & $\begin{array}{l}\text { Percentage } \\
\text { Elongation } \\
{[\%]}\end{array}$ \\
\hline Sample 1 & 47.03 & 106.33 & 111.05 & 11.50049 \\
\hline Sample 2 & 43.07 & 106.08 & 110.06 & 10.17034 \\
\hline Sample 3 & 40.73 & 109.34 & 114.09 & 9.92717 \\
\hline Mean & 43.61 & 107.25 & 111.73 & 10.53267 \\
\hline $\begin{array}{l}\text { Standard } \\
\text { Deviation }\end{array}$ & 3.18492 & 1.81597 & 2.09857 & 0.84693 \\
\hline \multicolumn{5}{|c|}{ (b) $1^{\text {st }}$ pass of ARB process } \\
\hline & $\begin{array}{l}\text { Modulus E } \\
\text { [Gpa] }\end{array}$ & $\begin{array}{l}\text { Tensile Stress at } \\
\text { Yield (offset } 0.2 \% \text { ) } \\
\text { [Mpa] }\end{array}$ & $\begin{array}{l}\text { UTS } \\
{[\mathrm{Mpa}]}\end{array}$ & $\begin{array}{l}\text { Percentage } \\
\text { Elongation } \\
{[\%]}\end{array}$ \\
\hline Sample 1 & 36.38 & 123.31 & 129.99 & 3.12404 \\
\hline Sample 2 & 31.67 & 120.33 & 125.70 & 3.52717 \\
\hline Sample 3 & 36.86 & 114.89 & 125.59 & 3.93064 \\
\hline Mean & 34.97 & 119.51 & 127.10 & 3.52728 \\
\hline $\begin{array}{l}\text { Standard } \\
\text { Deviation }\end{array}$ & 2.87103 & 4.26867 & 2.51062 & 0.40330 \\
\hline \multicolumn{5}{|c|}{ (c) $2^{\text {nd }}$ pass of ARB process } \\
\hline & $\begin{array}{l}\text { Modulus E } \\
\text { [Gpa] }\end{array}$ & $\begin{array}{l}\text { Tensile Stress at } \\
\text { Yield (offset } 0.2 \% \text { ) } \\
{[\mathrm{Mpa}]}\end{array}$ & $\begin{array}{l}\text { UTS } \\
{[\mathrm{Mpa}]}\end{array}$ & $\begin{array}{l}\text { Percentage } \\
\text { Elongation } \\
{[\%]}\end{array}$ \\
\hline Sample 1 & 38.62 & 114.17 & 119.49 & 4.55906 \\
\hline Sample 2 & 37.60 & 115.17 & 120.33 & 4.53647 \\
\hline Sample 3 & 38.52 & 115.11 & 120.81 & 5.14048 \\
\hline Mean & 38.25 & 114.81 & 120.21 & 4.74533 \\
\hline $\begin{array}{l}\text { Standard } \\
\text { Deviation }\end{array}$ & 0.55904 & 0.56269 & 0.66916 & 0.34239 \\
\hline
\end{tabular}


International Journal of Engineering Research and Technology. ISSN 0974-3154 Vol.13, No.4 (2020), pp. 783-792

(C) International Research Publication House. https://dx.doi.org/10.37624/IJERT/13.4.2020.783-792
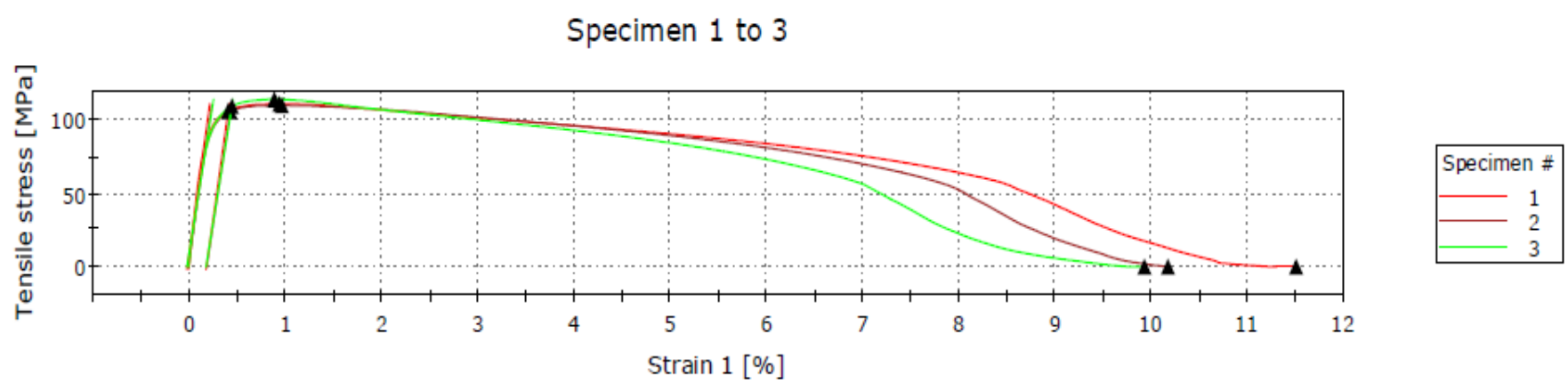

(a)

\section{Specimen 1 to 3}
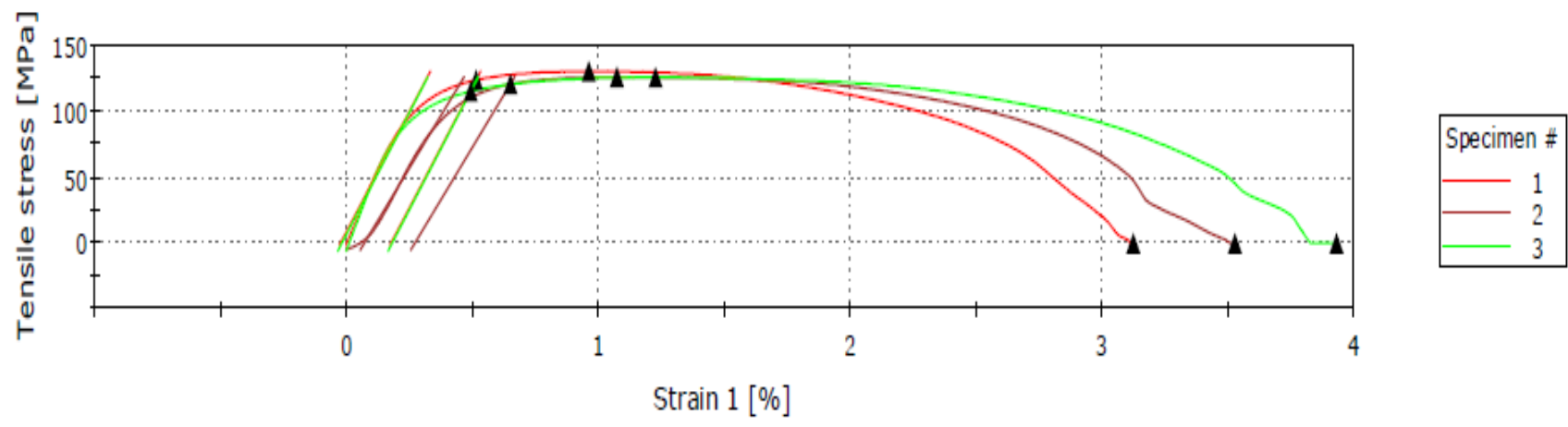

(b)

\section{Specimen 1 to 3}
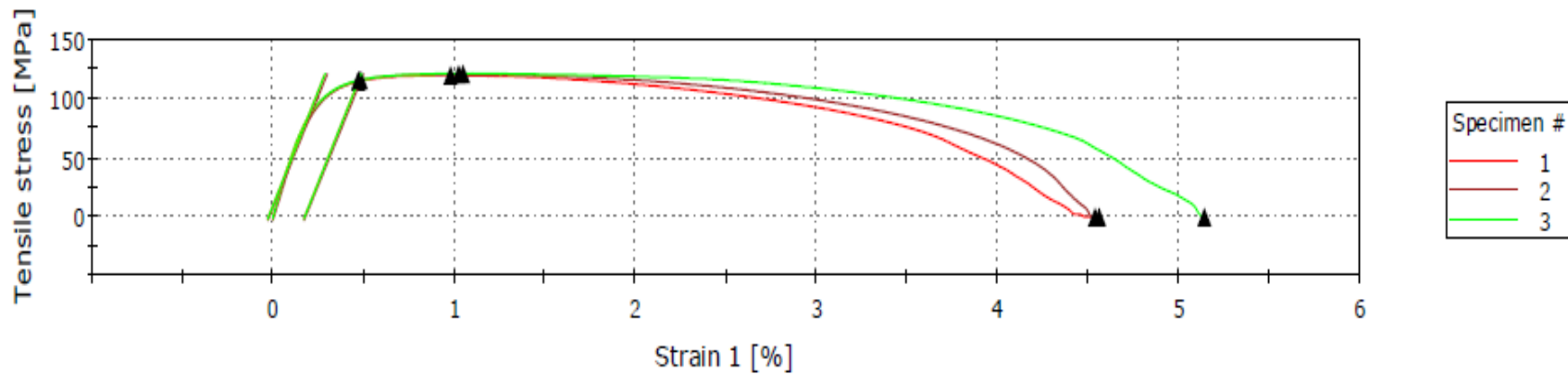

(c)

Figure 3: stress -strain curves of (a) parent sample, (b) first pass of ARB process and (c) second pass of ARB process.

Results reported in table 4 are graphically presented in figure 3 (a-c). The tensile stress-strain curves obtained from the tensile testing of the parent sample, first pass and second pass of ARB processed material are shown in fig. 3 (a-c). The ARBprocessed material, however, does not exhibit a sharp yield point and serrated flow in the stress-strain curve. The original sample shows the lowest yield stress of $107.25 \mathrm{MPa}$ while the highest was reported to be $119.51 \mathrm{MPa}$ after first pass of the ARB process. The ductility, which is measured in terms of total elongation, is the lowest for the first pass of the ARB-processed material. There is a decrease by approximately $67 \%$ in elongation due to the ARB process. The ultimate tensile strength (UTS) increases due to the ARB process. It was also observed that the UTS is higher after the $1^{\text {st }}$ pass and was reported as $127.10 \mathrm{MPa}$. The UTS and tensile stress at yield decreases after $2^{\text {nd }} A R B$ pass, where the material experience particle growth. The E-modulus decreases during the ARB process. Material particle size decreases after $1^{\text {st }}$ ARB cycle enhance the material properties (YS and UTS). 


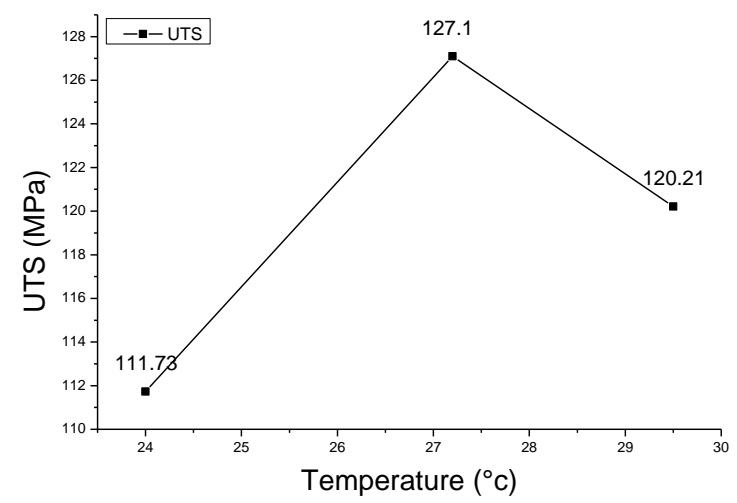

(a)

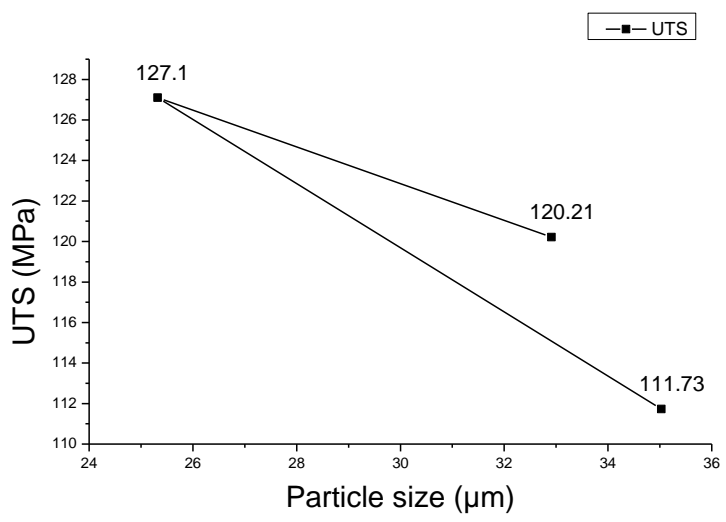

(b)

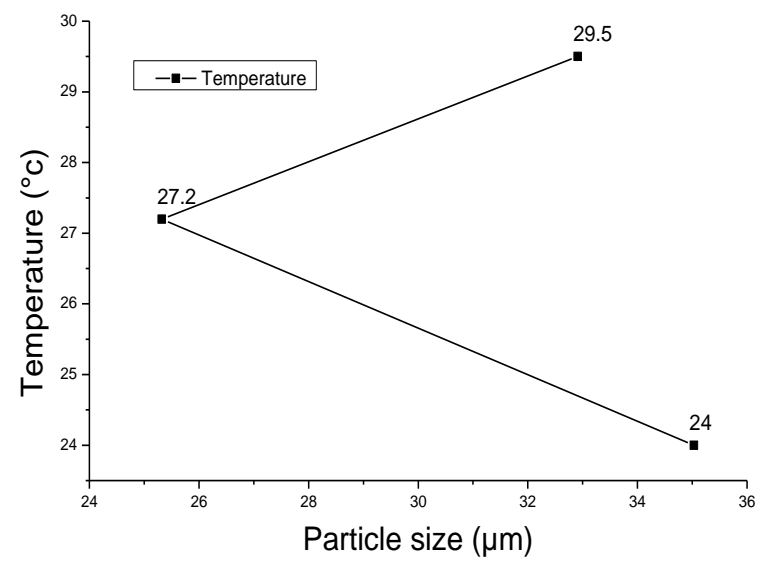

(c)

Figure 4: (a) UTS against temperature, (b) UTS against particle size and (c) temperature against particles of ARB process.

Figure 4a revealed that ARB process increases material temperature. After several rolling process, when the temperature reached $29.5^{\circ} \mathrm{C}$, ultimate tensile strength drops. Which indicate that material loss its properties. The decrease in particle size increases the UTS which is shown in figure $4 \mathrm{~b}$. From the same figure, this study shows that the increase in particle size decreases the UTS. Figure $4 c$ shows that the decrease in particle size increases material temperature, continues increasing in surface temperature results in particle growth. After experimentation, it was necessary to derive theoretical models of energy, stress and strain based on the observation of change of particle sizes during ARB.

\subsection{Theoretical modeling of change of particle sizes during ARB process}

The first law of thermodynamics, the conservation of energy principle, states that energy can be neither created nor destroyed; it can only change forms [16]. A closed system can exchange energy with its surroundings through heat and work transfer. Meaning, work and heat are the forms that energy can be transferred across the system boundary [16]. From the first law point of view, there is no difference between heat transfer and work, they are both energy interactions [16]. The fundamental law in physics describe heat energy and mechanical energy (work) in a system at the beginning and at the end of a thermodynamic cycle. A complete thermodynamic cycle can be described by the process of heat generated and the work to the system given by

$$
Q-W=0
$$

Where Q is the net heat transfer and W is work done. During ARB process which involved intrinsic energy process, heat supplied, and work done during deformation process. The heat supplied and work done during ARB process varies due to change of quantity of heat supplied by the materials during $\mathrm{ARB}$ and the expression can be given as

$$
d u=d Q-\sigma r^{3}
$$

Whereby dQ is internal heat in the material during ARB and $\sigma \mathrm{r}^{3}$ is the work done on the material. To better analyze the 
complexity of ARB process during deformation, we can extend the first law of thermodynamics to entropy differential analysis in a close system. By doing this, the change in internal heat is included and the thermal activation energy in the materials during ARB process is involved. This can be described mathematically as follows:

$d Q=-\left(T_{e x} d s-T_{e x} d P_{S}\right)+A_{e}-\frac{E_{a}}{R T}$

Whereby $A_{e}-\frac{E_{a}}{R T}$ is the activation energy in the material during ARB process which affects the internal heat in the material and the materials properties. It is important to recall that temperature severely affect materials properties during manufacturing and must be closely monitored. Equation (2) is modified by taking into consideration the derived expression of change in internal heat due to entropy and thermal activation during ARB process can be expressed as follows:

$$
d u=-\left(T_{e x} d s-T_{e x} d P_{S}\right)+A_{e}-\frac{E_{a}}{R T}-\sigma r^{3} d r
$$

Equation (4) is the derived change in internal energy during ARB. This affect several material properties since heat energy greatly affect material properties. This study aims at modeling particle growth due to rise in material temperature during ARB process, it is important to look at the material heat capacity during ARB process. From first principle, heat capacity is proportional to the material heat and the change in temperature during ARB given as $=\frac{Q}{\Delta T}$. Therefore, the change in temperature during $\mathrm{ARB}$ and it impact in heat capacity and heat transfer can be estimated using the following equation:

$$
\Delta \mathrm{T}=\frac{\mathrm{Q}}{\mathrm{C}}
$$

Whereby $\mathrm{C}$ is the heat capacity, $\mathrm{Q}$ is the heat transfer and $\Delta T$ change in temperature. The material heat capacity and heat transfer which affect the materials temperature increase with the rate of straining in the material during ARB process. This affects the material energy (strain energy) during ARB process. The change in strain energy during ARB process can be derived by considering the stress and strain along the rolling direction, transverse direction and longitudinal direction during ARB process. It is important to first formulate the equation describing the relationship of the total strain energy in the material during ARB process before involving their stress and strain parameters. The expression for the total strain energy during ARB is given as $\Delta E=W_{1}+W_{2}+W_{3}$ whereby $W_{3}$ is component of strain. By considering the stress, strain and the different rolling directions, the change in strain energy during
$\mathrm{ARB}$ can be given as

$$
\Delta E=\delta \frac{4}{3} \pi r^{3}+\phi(t) \sigma\left(\frac{4}{3} \pi r_{0}-\frac{4}{3} \pi r^{3}\right)+\varepsilon_{r}(t)
$$

Whereby the normalized strain energy can be written as

$$
\begin{gathered}
\frac{\Delta E}{E_{0}}=\frac{\sigma \frac{4}{3} \pi r^{3}}{\phi(t) \sigma \frac{4}{3} \pi r^{3}}+\frac{\phi(t) \sigma\left(\frac{4}{3} \pi r_{0}-\frac{4}{3} \pi r^{3}\right)}{\phi(t) \sigma \frac{4}{3} \pi r^{3}} \\
+\frac{\varepsilon_{r}(t)}{\phi(t) \sigma \frac{4}{3} \pi r^{3}}
\end{gathered}
$$

The expression for the strain energy during ARB can be further simplify by considering the Change in temperature with respect to size during $\mathrm{ARB}$ as $d Q=-\left(T_{e x} d_{s}-d P_{s} T_{e x}\right)$ and work done during ARB given as

$$
d w=F S=\sigma r^{2} d r
$$

As a result:

$$
\begin{array}{r}
d E=\frac{\sigma \frac{4}{3} \pi r^{3}\left(\varepsilon_{r}\right)}{\phi(t) \sigma \frac{4}{3} \pi r^{3}\left(\varepsilon_{r}\right)}+\frac{\phi(t) \sigma\left(\frac{4}{3} \pi r_{0}-\frac{4}{3} \pi r^{3}\right)\left(\varepsilon_{r}\right)}{\phi(t) \sigma \frac{4}{3} \pi r^{3}\left(\varepsilon_{r}\right)} \\
+\frac{\varepsilon_{r}(t)}{\phi(t) \sigma \frac{4}{3} \pi r^{3}}-\left(T_{e x} d_{s}-d P_{s} T_{e x}\right) \\
+\sigma r^{2} d r
\end{array}
$$

Equations (1-8) are solved simultaneously using Engineering Equation Solver software (F-Chart Software, Madison, W153744, USA).

\section{MODEL RESULTS AND DISCUSSION}

The proposed models derived in this paper are tested with the following data of nanocrystalline aluminium sample [17] , $M_{o}=0.01 \mathrm{~nm}^{2} \mathrm{~s}^{-1}, m=4, C C=12, a=0.90, D=10^{-4}$, $h_{0}=0.25 \mathrm{~nm}, T_{m}(\infty)=933.47 \mathrm{~K}, C V_{0}=0.3, H_{m}(\infty)=10.71$ $\mathrm{KJMol}^{1}, \sigma_{0}{ }^{\prime}=16.7 \mathrm{MPa}, K_{t}=1.3, \sigma_{0}=15.40 \mathrm{MPa}$, $K_{d}=1301.77 \mathrm{MPa} \_\mathrm{nm}^{1 / 2}, R=8.31 \mathrm{JK}^{-1} \mathrm{~mol}^{-1}$, and $T_{r}=300$ K. $\tau=0.000008 r_{o}=100 \mathrm{~nm}, c=1.1, b=0.0035, A=0.4, F=1 \mathrm{kN}$, , $P C=1.95, \sigma=96.8 \mathrm{Nm}, P=27500 \mathrm{~N} / \mathrm{m}^{2}, G=169 \mathrm{Gpa}$, and $v=0.23$. The additional data obtained from this work are, $\varepsilon r=29419.95 \mathrm{~N}, \quad E a=27500 \mathrm{KJ} / \mathrm{mol}, \quad T \exp 0=297.25 \mathrm{~K}$ Texp $1=300.35 \mathrm{~K}, \operatorname{Texp} 2=302.65 \mathrm{~K}$. The obtained results in the study are presented and discussed in Figures (5-7). 
International Journal of Engineering Research and Technology. ISSN 0974-3154 Vol.13, No.4 (2020), pp. 783-792

(C) International Research Publication House. https://dx.doi.org/10.37624/IJERT/13.4.2020.783-792

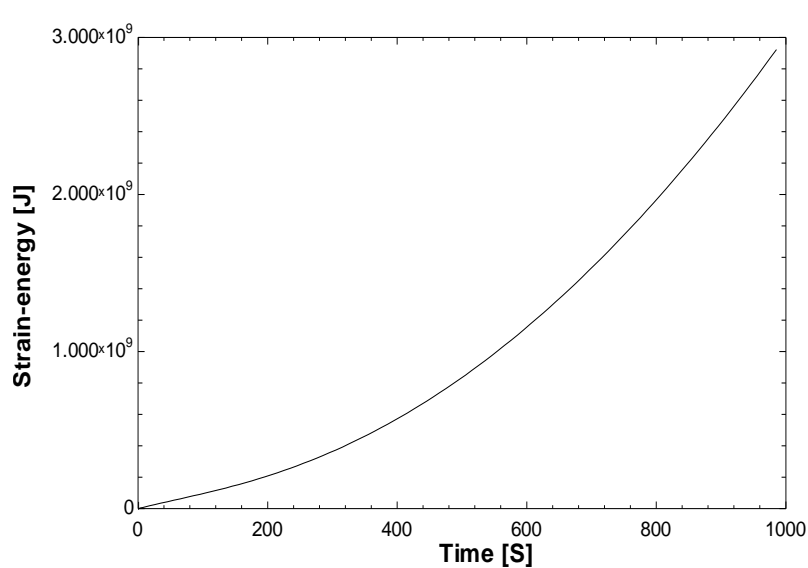

(a)

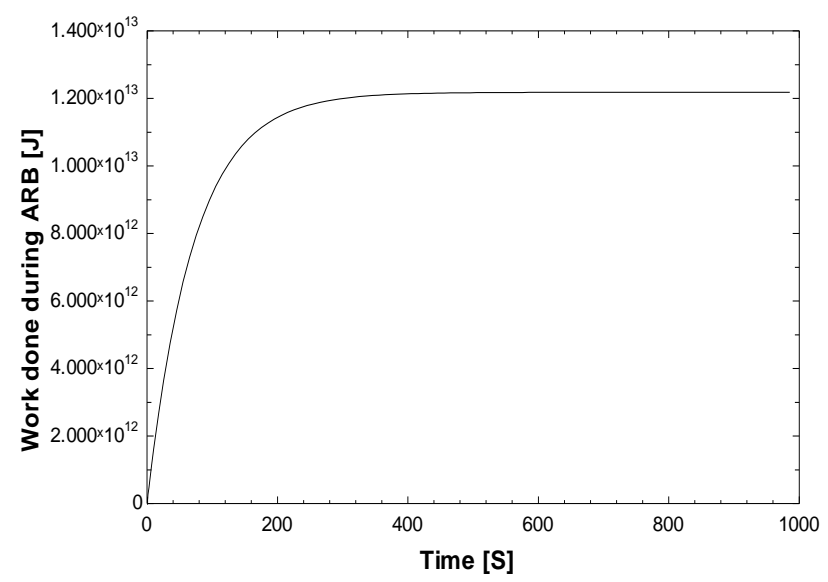

(c)

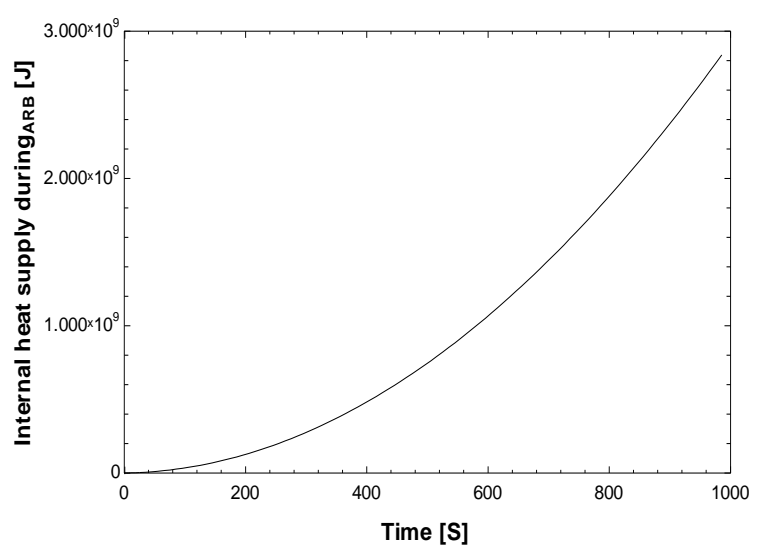

(b)

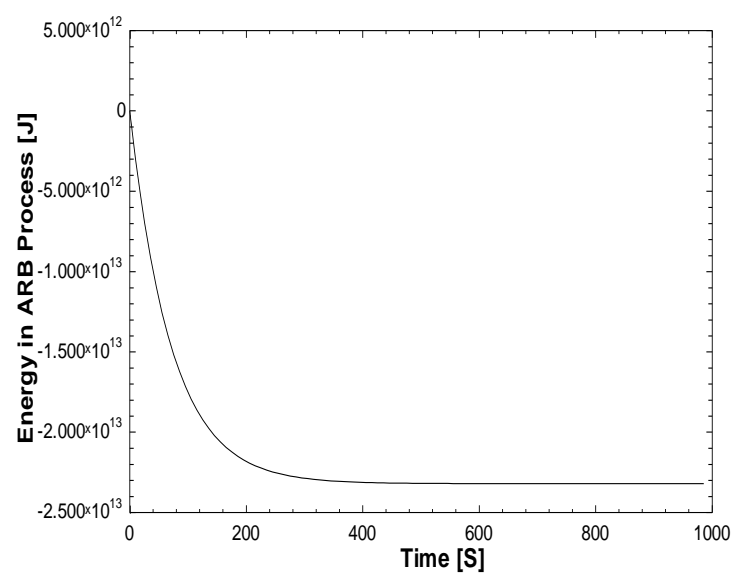

(d)

Figure 5: (a) strain energy [J] against time [S], (b) internal heat supply during ARB against time [S], (c) work done during ARB [J] against time [S] and energy during ARB [J] against Time [S]

It is observed from Fig.5 (a) that the material strain energy increases with time during grain deformation of nanomaterials by ARB. Fig. 5 (b) revealed that the material internal heat supply increases with time during deformation of nanostructure materials. Fig. 5 (c) shows that the work done during ARB is rapidly increasing and was later observed to become constant during grain refinement. It is also shown as observed in Fig. 5 (d) that the energy in ARB process decreases as the time increases during grain refinement. These findings can be explained as follows: The increase of material strain energy with time can be explained by the mobility of atoms during $A R B$ results in more strains energy due to their very refined size. In the initial material, the atoms were larger and the impact on strain energy was relatively low as compared to the material at nanoscale level. Strain energy is affected by feed rate during ARB process which increases the mobility of the atoms at Nano scale level. This results in higher atoms vibration and increase of strain energy around grain boundaries. More strain energy is also created at the grain boundaries which increases the strain energy in the materials. Continuous grain refinement led to the creation of more grain boundaries which increases the material strain energy as shown in Fig. 5 (a). As ARB process takes place, grain boundaries dislocation motion also increases from lower boundaries to higher boundaries leading to increase in material strain energy. As ARB takes place, the internal energy supply increases with time due to adiabatic warming and continuous grain refinement leading to continuous increase in the material heat content as shown in Fig.5 (b). The mobility of atoms at Nano scale vibration induces more heat in the material and increases the heat content in the material due to their very small sizes. Fig. 5 (c) shows that the work done increases with time since more activities such as grain boundaries migration, grain coalesces, grain growth and atoms mobility increase during ARB process. The material energy is decreasing with time because deformation of material is based on bonding energy which affects the intrinsic properties of the material negatively during ARB. This is also because strain rate, internal energy and work done affect energy in a material. These activities also affect heat supply during ARB as shown in Fig.6 


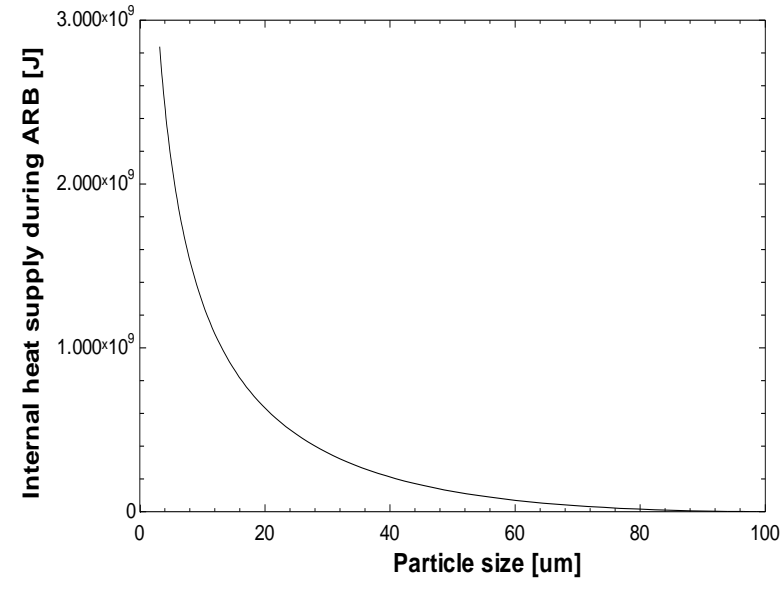

(a)

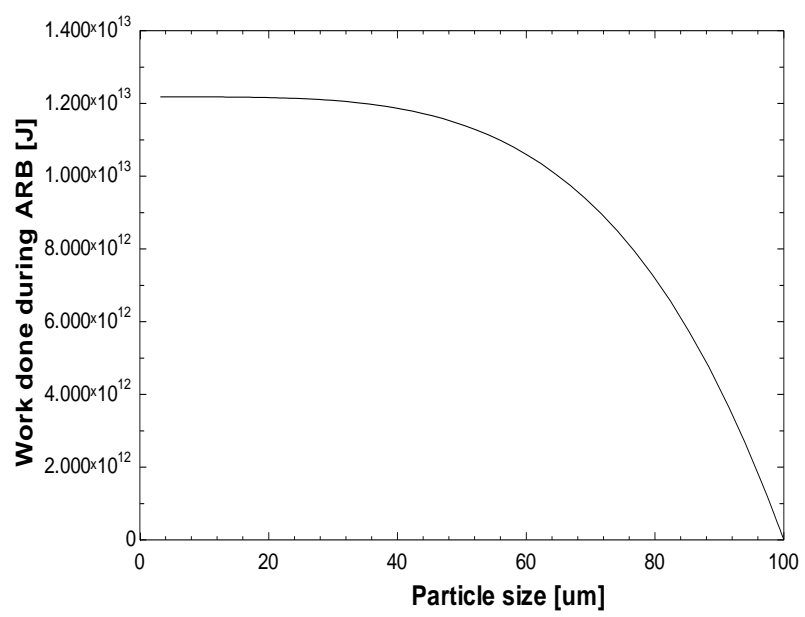

(c)

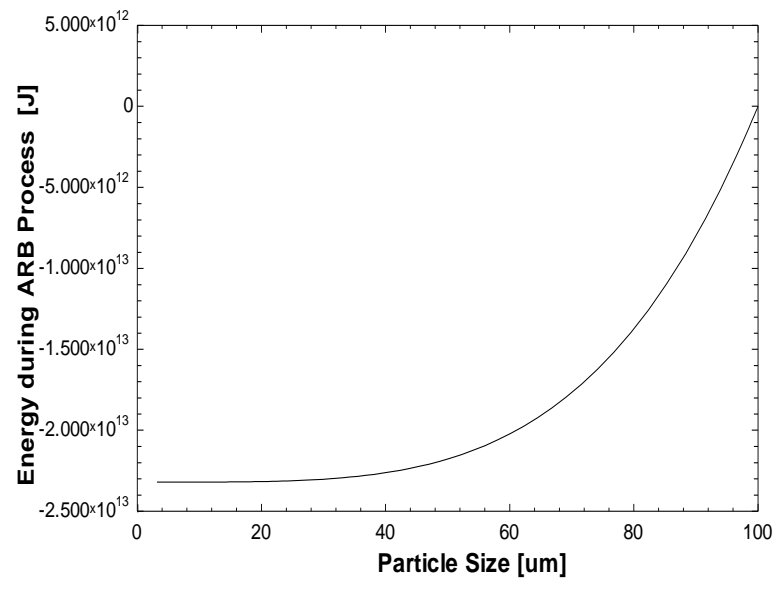

(b)

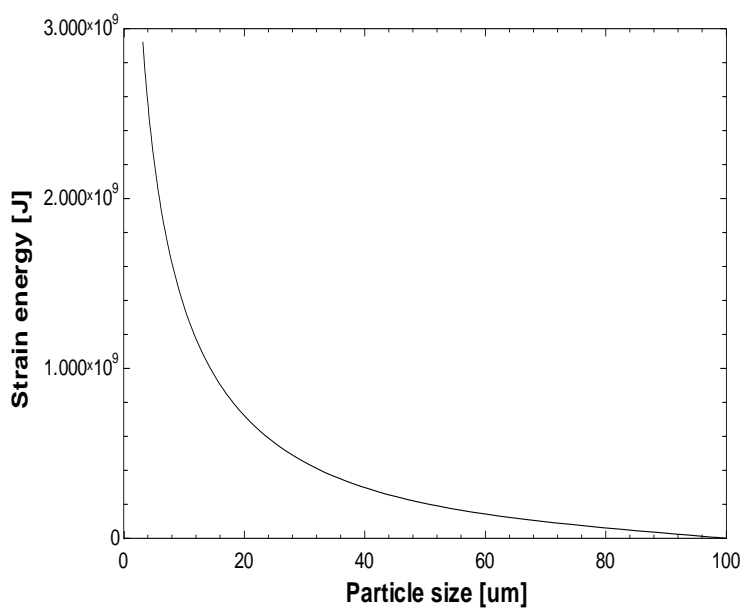

(d)

Figure 6: (a) Internal heat supply $[\mathrm{J}]$ against particle size $[\mu \mathrm{m}]$, (b) Energy during ARB against particle size $[\mu \mathrm{m}]$, (c) work done during ARB $[\mathrm{J}]$ against particle size $[\mu \mathrm{m}]$ and Strain energy $[\mathrm{J}]$ against particle size $[\mu \mathrm{m}]$.

It is observed from Fig.6 (a) that decrease in particle sizes lead to increase in internal energy during ARB. Fig. 6 (b) also shows that the material internal energy decreases as the particle sizes decreases during ARB. Fig. 6 (c) revealed that the work done increases as the particle size decreases. It is observed (as shown in Fig. 6 (d)) that the strain energy increases as the particle sizes decreases. The reason for these observations can be linked to the fact that nanomaterials have very high vibration and excitation energy at very small size. Their sizes are negatively affected by temperature leading to vibration and conduction of heat at very small sizes level. This explains why grain growth can start happening at a very small size due to adiabatic warming. The surrounding grains conduct more heat to the material content which is one of the most difficult problems to control in the manufacturing of nanomaterials due to temperature that is usually high. Similarly, for the material energy during ARB process, as the particle size gets smaller, energy decreases during grain refinement. Nanomaterials are very sensitive to temperature and temperature lower their energy and property as shown in the research findings. Work done increases as particle sizes decreases due to increase in dislocation motion and grain boundaries migration that takes place due to monotonic deformation of material. The material strain energy suffers as particle decreases due to random vibration of atoms. This activates affect the mechanical properties of nanomaterials as shown in Fig. 7 

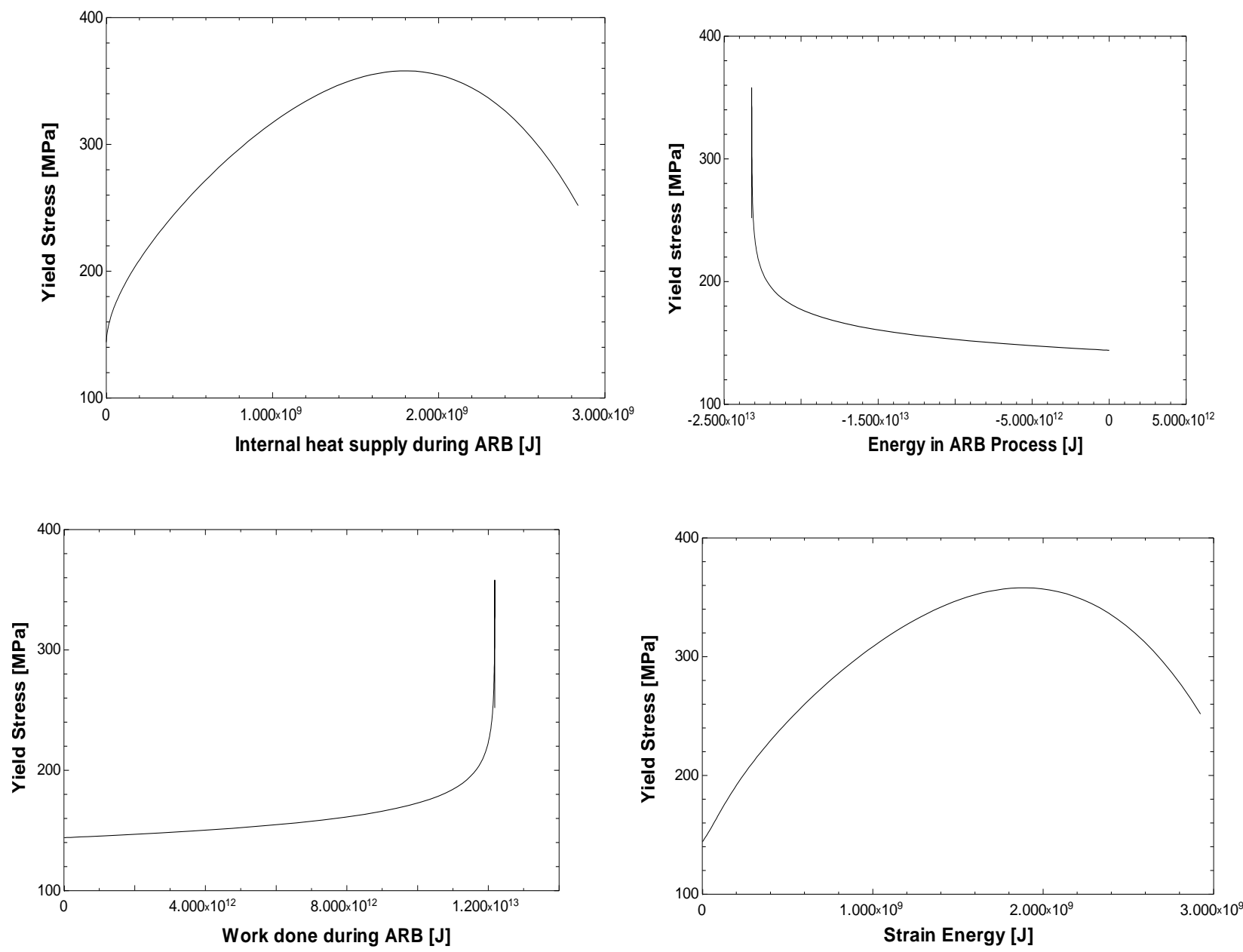

Figure 7: (a) Yield stress [MPa] against Internal heat supply during ARB process [J], (b) Yield stress [MPa] against Energy in ARB process [J], (c) Yield stress [MPa] against work done during ARB [J] and Yield stress [MPa] against energy during ARB [J].

Figure 7 (a) and Fig. 7 (d) are like the Hall-Petch relationship. Fig. 7 (b) shows that as energy decreases the yield stress increases during ARB. Fig. 7 (c) that the yield stress increases as the work done increase during ARB. These changes can be explained as follows. During ARB process more grain dislocation motion and more grain migration takes place as the grain curvature moved from lower to higher curvature. This enhances the yield stress of the nanomaterial as shown in Fig. 7 (a) and Fig.7 (d). However, the continuous decrease in sizes doesn't lead to properties enhancement as the material yield stress was observed to decrease at a later stage as shown in Fig. 7 (a) and Fig. 7 (d). The increase in energy in the material led to adiabatic warming which negatively affect the material property as shown in Fig.7 (b). The work done was reported to increase the material dislocation motion and grain migration which impacted grain boundaries transition and enhanced yield stress as shown in Fig. 7 (c).

\section{CONCLUSION AND RECOMMENDATION}

The current study was aimed at studying the heat content of nanomaterials during grain refinement by ARB. To achieve this aim, a theoretical model of nanomaterial heat energy during ARB was develop based on microscopy analysis on how dislocation motion and strain energy affected grain mobility and grain boundaries dislocation. This affected the curvature of grain from low and high curvature as well as impacted properties during grain refinement. Microscopy analysis was used to characterise the internal mobility of grains during dislocation motion. The theoretical model was developed based on the microscopy observation to test the impact of activation energy on grain properties during ARB. The following facts were revealed and validated experimentally. The microstructure after second ARB pass shows an interface between two particles layers which are straight and adherent due to material being piled during ARB process. Different particle curvature and dislocation were observed after different passes during grain refinement and this impacted the material properties. Particle growth was noticed after 2nd ARB pass. After several ARB passes, when the temperature reached $29.5^{\circ} \mathrm{C}$ ultimate tensile strength drops relating to decrease in properties. The decrease in particle size increases material temperature and continues increasing in surface temperature results in particle growth. The material strain energy increases 
as time increases during grain deformation. Material internal heat supply increases as time increases during deformation of nanostructure materials. The decrease in particle sizes lead to increase in internal energy during ARB. Material internal energy decreases as the particle sizes decreases during ARB. Strain energy increases as the particle sizes decreases.

\section{ACKNOWLEDGEMENT}

The research is supported by the University of Johannesburg and University of South Africa. The relevant experiments and simulations were performed using Engineering Equation Solver (EES).

\section{REFERENCE}

[1] B. K. Teo and X. H. Sun, "From top-down to bottom-up to hybrid nanotechnologies: Road to nanodevices," $J$. Clust. Sci., vol. 17, no. 4, pp. 529-540, 2006.

[2] I. M. Elseaidy, M. M. Ibrahim, M. M. Ghoneim, and M. E. A. EL-Azim, "Aluminum alloys strengthening by accumulative roll- bonding (arb) process," Trans. SMiRT, pp. 1-10, 2007.

[3] H. Sheikh and E. Paimozd, "Effect of Hot Accumulative Roll Bonding Process on the Mechanical Properties of AA5083," Open J. Met., vol. 01, no. 01, pp. 12-15, 2011.

[4] T. B. Tengen, "Designing nanomaterials with desired mechanical properties by constraining the evolution of their grain shapes.," Nanoscale Res. Lett., vol. 6, no. 1, p. $585,2011$.

[5] A. P. Zhilyaev, G. V. Nurislamova, B. K. Kim, M. D. Baró, J. A. Szpunar, and T. G. Langdon, "Experimental parameters influencing grain refinement and microstructural evolution during high-pressure torsion," Acta Mater., vol. 51, no. 3, pp. 753-765, 2003.

[6] J. Bogucka, "Influence of Temperature of Accumulative Roll Bonding on the Microstructure and Mechanical Properties of AA5251 Aluminum Alloy," Arch. Metall. Mater., vol. 59, no. 1, pp. 16-20, 2014.

[7] S. Roy, B. R. Nataraj, S. Suwas, S. Kumar, and K. Chattopadhyay, "Accumulative roll bonding of aluminum alloys 2219/5086 laminates: Microstructural evolution and tensile properties," Mater. Des., vol. 36, pp. 529-539, 2012.

[8] A. Fattah-alhosseini, O. Imantalab, Y. Mazaheri, and M. K. Keshavarz, "Microstructural evolution, mechanical properties, and strain hardening behavior of ultrafine grained commercial pure copper during the accumulative roll bonding process," Mater. Sci. Eng. A, vol. 650, pp. 814, 2016.

[9] H. Miura, G. Yu, and X. Yang, "Multi-directional forging of AZ61Mg alloy under decreasing temperature conditions and improvement of its mechanical properties," Mater. Sci. Eng. A, vol. 528, no. 22-23, pp. 6981-6992, 2011.
[10] G. Guisbiers, "Size-dependent materials properties toward a universal equation," Nanoscale Res. Lett., vol. 5, no. 7, pp. 1132-1136, 2010.

[11] H. M. Lu and Q. Jiang, "Size-Dependent Surface Energies of Nanocrystals," J. Phys. Chem. B, vol. 108, no. 18, pp. 5617-5619, 2004.

[12] T. sob, P Baonhe;Alugongo, A ALfayo; Tengen, "The Effects of the Size Variants of Nanocrystalline Materials Produced by Accumulative Roll-Bonding on their Energy ...," no. October, 2016.

[13] P. B. Sob, "Stochastic Model of Nanocrystalline Materials Energy Produced by Accumulative RollBonding," no. October, 2016.

[14] J. C. Bhatt and K. Kholiya, "Effect of size on the elastic and thermodynamic properties of nanomaterials," Indian J. Pure Appl. Phys., vol. 52, no. 9, pp. 604-608, 2014.

[15] P. B. Sob, A. A. Alugongo, and T. B. Tengen, "The Effects of the Size Variants of Nanocrystalline Materials Produced by Accumulative Roll-Bonding on their Energy , Thermodynamics and Mechanical Properties," no. October, pp. 1-10, 2016.

[16] Bahrami M., "Chapter 3 : The First Law of Thermodynamics : Closed Systems Modes of Heat Transfer," vol. 388, pp. 1-15, 2005.

[17] P. B. Sob, A. A. Alugongo, and T. B. Tengen, "The Effect of deformation activation volume, strain rate sensitivity and processing temperature of grain size variants The Effect of Deformation Activation Volume, Strain Rate Sensitivity and Processing Temperature of Grain Size Variants," no. November, 2015. 